\title{
Surgical Curriculum for Presbyopia-Correcting Intraocular Lenses: Resident Experiences and Surgical Outcomes
}

\author{
Kamran M Riaz $\mathbb{D}^{1,2}$ \\ Blake L Williams' \\ Asim V Farooq' \\ Carolyn E Kloek ${ }^{2}$
}

'Department of Ophthalmology and Visual Science, University of Chicago Medical Center, Chicago, IL 60637, USA;

${ }^{2}$ Dean McGee Eye Institute, University of Oklahoma Health Sciences Center,

Oklahoma City, OK 73104, USA

\section{Video abstract}

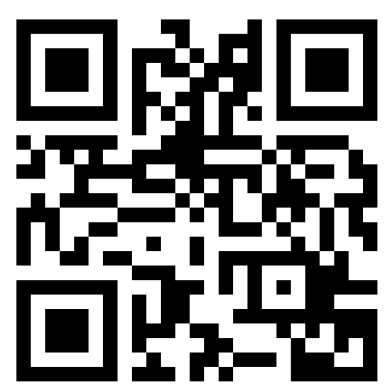

Point your SmartPhone at the code above. If you have a $Q R$ code reader the video abstract will appear. Or use: https://youtu.be/OHbPTPD6Kjw
Correspondence: Kamran M Riaz

Dean McGee Eye Institute, University of Oklahoma Health Sciences Center, 608

Stanton L. Young Blvd, Suite 3/3,

Oklahoma City, OK 73104, USA

Tel + | 405-27I-1095

Fax + 405-27I-3680

Email Kamran-Riaz@dmei.org
This article was published in the following Dove Press journal: Clinical Ophthalmology

Objective: To describe a stepwise surgical curriculum that was implemented to teach novice surgeons about currently available advanced technology intraocular lenses (ATIOLs) for correction of presbyopia and to report the experiences and surgical results of ATIOL surgery performed by residents who engaged in the curriculum.

Design, Setting, and Participants: Third-year ophthalmology residents participated in a curriculum incorporating didactic lectures (with objective assessment and wet-lab practice) and observation of attending-performed ATIOL surgeries prior to performing ATIOL surgery as primary surgeon under direct supervision. Post-operative outcomes studied were best corrected distance visual acuity (BCDVA) and uncorrected distance (UDVA), intermediate (UIVA) near (UNVA) visual acuity and correction of astigmatism with at least 3 months of follow-up (POM3+). Residents were also given a survey to assess experiences with the surgical curriculum, preparedness for use of ATIOLs post-residency, and ATIOL practice pattern post-residency.

Results: A total of 12 residents from four consecutive classes completed the curriculum. Residents overall had a favorable opinion of the curriculum and felt well prepared to use ATIOLs after training. Graduates who currently perform cataract surgery felt comfortable using all available ATIOLs. A total of 100 eyes from 72 patients met the inclusion criteria for analysis in the study. At the POM3 + timepoint, $88 \%$ of eyes had UDVA of 20/30 or better, $93 \%$ had UIVA of $20 / 30$ or better, and $71.2 \%$ had UNVA of 20/30 (J2) or better. Among eyes that received an astigmatism-correcting ATIOL, 91\% had $<1$ diopter of astigmatism after surgery.

Conclusion: Resident surgeons learned to perform ATIOL surgery (medical knowledge) and achieve strong surgical outcomes (patient care) with all currently available ATIOLs after completion of a stepwise curriculum. Educators may be encouraged to incorporate an ATIOL curriculum based on the results of this study. The curriculum presented is a prototype and may be further improved with future experiences and studies.

Keywords: cataract surgery curriculum, presbyopia-correcting intraocular lenses, advanced technology intraocular lenses, resident cataract surgery

\section{Plain Language Summary}

Recent years have seen an introduction of new intraocular lenses known as advanced technology intraocular lenses (ATIOLs) that help decrease the need for patients to need glasses for distance, intermediate, and near vision after cataract surgery. Currently, residents have very limited exposure to ATIOL surgery, including experience with all currently available ATIOLs from various manufacturers. We sought to therefore develop 
a curriculum to teach residents how to use all currently available ATIOLs in the United States to supplement and enhance an existing standard cataract surgery curriculum. We successfully implemented this curriculum to four consecutive graduating classes while maintaining patient safety and meeting resident proficiency requirements. Residents reported they felt better prepared to practice the full spectrum of ATIOL surgery after residency. Surgical results of our resident cohort are comparable to those reported by experienced ATIOL surgeons in the literature. We propose that our novel ATIOL curriculum may be implemented and further modified by other residency programs to enhance their own respective cataract surgery curricula.

\section{Introduction}

Cataract surgery is both a restorative and refractive surgical procedure as patients are increasingly interested in and motivated for surgical options to optimize distance, intermediate and near vision to minimize the need for spectacles postoperatively. Standard cataract surgery is performed with the placement of a monofocal intraocular lens (IOL), usually set for a distance focal point. While patients typically report improved distance vision after surgery, the vast majority of patients will require presbyopia-correcting spectacles for near vision tasks. Recent years have seen a significant increase in the availability of advanced technology intraocular lenses (ATIOLs) for the surgical correction of presbyopia, including: diffractive multifocal IOLs (MFIOLs) with different add powers; extended depth of focus (EDOF) IOLs; and accommodating IOLs (AIOLs), including ATIOLs with astigmatism correction (toric) options. Given the abundance of ATIOL choices and patient expectations, even experienced surgeons have had to quickly learn and adapt new technology into their surgical practices.

Ophthalmology surgical educators have a primary responsibility to teach trainees how to perform safe and effective standard cataract surgery in order to achieve surgical competence and adequately prepare them for the post-training phase of their career. Recently, there has been a reported trend in regards to the increasing popularity of ATIOLs in surgeons' practice. The American Society of Cataract and Refractive Surgery (ASCRS) Clinical Survey from 2018 reported that $79 \%$ of cataract surgeons currently use presbyopia-correcting IOLs. ${ }^{1}$ Surgical educators therefore face the challenge of not only teaching standard cataract surgical techniques, but the appropriate use of ATIOLs. Currently, there are no minimum requirements or recommendations by the
American College of Graduate Medical Education (ACGME) or by the Association of University Professors of Ophthalmology (AUPO) for residents to perform ATIOL surgery, which likely explains the paucity of structured educational programs in this area.

Residents in training are similarly increasingly motivated to learn about the full spectrum of ATIOL technology in order to better transition to the post-training phase of their career. While there is interest from both surgical educators and trainees, recent data suggest that resident experiences with ATIOLs can be improved. ${ }^{2}$ An earlier study (2013) reported that $78 \%$ of respondents had not implanted an ATIOL, and $77 \%$ felt their exposure to this technology was inadequate. ${ }^{3}$ When considering both trainee surgeons as well as surgeons in their first 5 years of practice, a 2017 study reported only $39 \%$ of respondents had performed ATIOL surgery. ${ }^{4}$ These data suggest an increasing adoption of ATIOL surgeries among practicing surgeons for which a structured ATIOL curriculum may uniquely benefit surgeons in training.

A growing number of surgical educators are interested in and have been teaching ATIOL surgery to their trainees. However, strategies to efficaciously incorporate the full range of ATIOL types into existing surgical curricula have not been reported in the literature. A dual challenge exists in this regard: surgical educators must consider how best to incorporate ATIOLs into their curriculum without sacrificing primary cataract surgical education and resident surgeons must acquire additional knowledge and skills for ATIOL surgery.

Multiple studies have shown that quality visual outcomes after standard cataract surgery can be obtained throughout residency training, especially when coupled with a teaching curriculum and increased surgical volume. ${ }^{5-8}$ We hypothesized that a step-wise ATIOL curriculum could enhance a standard cataract surgery curriculum without negatively affecting primary teaching objectives or resident surgical case volumes. Here we describe our ATIOL surgical curriculum, and report the experiences of residents who completed the curriculum and the results of resident-performed ATIOL surgery for four residency classes.

\section{Materials and Methods}

This retrospective study was approved by the Institutional Review Board (IRB) of the University of Chicago Medical Center (IRB18-0948). The IRB waived the requirement for informed consent for review of medical records as it was determined there was minimal/no risk to patients or residents being studied. This work adhered to the tenets of the 
Declaration of Helsinki. Patient data confidentiality was maintained throughout the study and manuscript preparation process.

The medical records of patients who met the inclusion criteria and had resident-performed ATIOL surgery during the study period (July 2015-December 2018) were reviewed. Inclusion criteria included a diagnosis of visually significant cataract affecting a patient's activities of daily living (that underwent cataract surgery); absence of preoperative corneal or retinal disease; placement of ATIOL; and at least three-month post-surgical follow-up. Exclusion criteria included intraoperative surgical events precluding use of ATIOL and post-operative complications requiring surgical intervention. The same attending surgeon (KMR) supervised all preoperative visits, discussion with patients regarding patients' choice of ATIOL, resident-performed ATIOL surgeries and post-operative visits.

We developed a three-phase, stepwise surgical curriculum to incorporate the use of available ATIOLs into our existing resident cataract surgery education program (Table 1). Each phase had specific objectives, teaching methods and assessment criteria. The same attending surgeon also supervised all phases of the surgical curriculum. Full details of the curriculum, including lecture slides and educational materials, are available upon communication with the corresponding author (KMR). Brief details are provided below.

Table I The ATIOL Surgical Curriculum

\begin{tabular}{|c|c|c|c|}
\hline & Objectives & Teaching Methods & Assessment Methods \\
\hline $\begin{array}{l}\text { Phase } \\
\text { I }\end{array}$ & $\begin{array}{l}\text { To learn the basics of ATIOL } \\
\text { technology: } \\
\text { I. How to select appropriate candi- } \\
\text { dates for ATIOL surgery } \\
\text { 2. Risks/benefits of ATIOLs, including } \\
\text { alternatives for presbyopia correc- } \\
\text { tion (monovision, etc.) } \\
\text { 3. Overview of all currently available } \\
\text { non-toric and toric ATIOLs includ- } \\
\text { ing advantages and disadvantages of } \\
\text { each model }\end{array}$ & $\begin{array}{l}\text { Didactic lectures, including use of surgical videos, } \\
\text { given early in the academic year by the surgical } \\
\text { educator(s) } \\
\text { - Wet-lab environment to practice ATIOL insertion, } \\
\text { centration and rotation in animal eye and artificial } \\
\text { eye models }\end{array}$ & $\begin{array}{l}\text { - Multiple-choice test given at end of lectures to } \\
\text { assess residents' knowledge of ATIOLs } \\
\text { - Supervising faculty overseeing wet-lab environment } \\
\text { to assess residents' abilities in regards to technical } \\
\text { skills necessary for ATIOL surgery (insertion and } \\
\text { rotation of ATIOL, etc.) through direct observation } \\
\text { and additional instruction, if needed }\end{array}$ \\
\hline $\begin{array}{l}\text { Phase } \\
2\end{array}$ & $\begin{array}{l}\text { To demonstrate sufficient knowledge } \\
\text { about ATIOL surgery, including: } \\
\text { I. Preoperative counseling } \\
\text { 2. Preoperative ATIOL selection } \\
\text { 3. Intraoperative steps of ATIOL } \\
\text { surgery } \\
\text { 4. Postoperative management }\end{array}$ & $\begin{array}{l}\text { Direct observation of supervising faculty perform- } \\
\text { ing preoperative exam, including use of appropriate } \\
\text { diagnostic tools and imaging; patient expectations; } \\
\text { and appropriate ATIOL choice to determine ATIOL } \\
\text { candidacy } \\
\text { - Direct observation of supervising faculty perform- } \\
\text { ing other preoperative steps for ATIOL surgery } \\
\text { (calculating the power of the ATIOL, model of the } \\
\text { ATIOL, etc.) } \\
\text { - Direct observation of supervising faculty perform- } \\
\text { ing ATIOL surgery } \\
\text { Direct observation of supervising faculty examining } \\
\text { patients in the postoperative period, including dis- } \\
\text { cussions regarding satisfaction and need for post- } \\
\text { surgical management }\end{array}$ & $\begin{array}{l}\text { - Residents observe the supervising faculty perform at } \\
\text { least } 5 \text { complete preoperative examinations and } \\
\text { discussions for patients undergoing ATIOL surgery } \\
\text { - Residents to then practice the preoperative exam- } \\
\text { ination and discussion with patients undergoing } \\
\text { ATIOL surgery under direct observation by teaching } \\
\text { faculty } \\
\text { - Teaching faculty to intervene during any of these } \\
\text { steps in order to correct preoperative discussion } \\
\text { - Residents to practice ATIOL calculation, especially } \\
\text { for placement of toric ATIOLs and review these } \\
\text { calculations with teaching faculty } \\
\text { - Residents to observe and practice postoperative } \\
\text { management of patients who have previously } \\
\text { undergone ATIOL surgery }\end{array}$ \\
\hline $\begin{array}{l}\text { Phase } \\
3\end{array}$ & $\begin{array}{l}\text { To perform ATIOL surgery under } \\
\text { teaching faculty supervision }\end{array}$ & $\begin{array}{l}\text { - Residents perform ATIOL surgery under direct } \\
\text { supervision from teaching faculty }\end{array}$ & $\begin{array}{l}\text { - Residents receive objective assessment of ATIOL } \\
\text { surgery (ICO-OSCAR form), with emphasis given } \\
\text { to size/centration of capsulorrhexis, centration of } \\
\text { ATIOL and on-axis placement of toric ATIOLs } \\
\text { - Residents review surgical video with attending sur- } \\
\text { geon after ATIOL surgery } \\
\text { - Additional wet-lab time employed as needed }\end{array}$ \\
\hline
\end{tabular}


Phase 1: Residents were first given instruction about the optical principles and technology involved in each ATIOL, advantages and disadvantages of each ATIOL, and review of published clinical results. Didactic lectures and videos (approximately 3-4 hours lecture time) were used to introduce preoperative principles such as patient selection (inclusion and exclusion criteria) and currently available ATIOLs (MFIOL, EDOF IOL, AIOLs and toric variants). Lecture titles included, "Introduction to Cataract Surgery with Advanced Technology Lenses", "Overview of Currently Available ATIOLs in the United States" and "Perioperative Management of ATIOL Surgery". Important aspects of clinical examination and interpretation of necessary pre-surgical diagnostic imaging were also reviewed. A thirty-question multiple-choice test was administered to assess understanding of the didactic material (Supplemental Material, Exhibit A). Residents then participated in an attending-supervised wet-lab environment early in the academic year (approximately 2-3 hours wet-lab time) to practice ATIOL insertion in animal and artificial eye models, especially AIOL insertion, given the extra surgical maneuvers associated with this ATIOL.

Phase 2: Residents performed face-to-face surgeonpatient discussions about ATIOLs, including risks and benefits, under the supervision of the attending surgeon. Trainees also observed the attending surgeon during the preoperative (counseling in clinic and appropriate ATIOL selection, including power calculation and model selection), intraoperative (performing ATIOL surgery), and postoperative (managing patient expectations and limitations) phases.

Phase 3: ATIOL surgical cases were performed by residents as primary surgeon under attending supervision. Residents also performed postoperative care under the supervision of the same attending surgeon to assess their surgical outcomes and maintain continuity of care. When deemed necessary by the surgical educator, some residents required additional time in the wet-lab during Phase 3.

Preoperatively, all patients received a complete ophthalmic examination including slit-lamp biomicroscopy, tonometry, refraction, keratometry (Topcon KR8000; Paramus, NJ), optical biometry (Lenstar LS900 (Haag-Streit Diagnostics, Switzerland) and dilated fundus examination. Topography was additionally performed on all patients found to have $>1.5 \mathrm{D}$ astigmatism on keratometry or optical biometry. Based on clinical findings during the dilated fundus exam, some patients underwent additional testing with optical coherence tomography of the macula to rule out any significant retinal pathology that would preclude the use of an ATIOL.

The choice of ATIOL depended on the preoperative discussion among the resident, attending surgeon and the patient, wherein a full explanation of the potential benefits and risks of each available ATIOL was discussed. Patients made the final decision to determine if they wanted an ATIOL and if so, which ATIOL model they wished to receive. They also gave consent for the resident to serve as primary surgeon under appropriate supervision. No patient was charged any additional fees for an ATIOL per institutional policy (ie residents at our institution have gratis access to all studied ATIOLs for educational purposes).

ATIOLs implanted in this study included diffractive multifocal IOLs (Alcon SN6AD1 and SV25T0; Johnson and Johnson ZKBOO, ZLBOO and ZMBOO models); extended depth of focus IOL models (Johnson and Johnson Symfony ZXROO); and an accommodating IOL model (Bausch and Lomb Crystalens AO1UV). ToricATIOLs included toric diffractive multifocal IOL models (Alcon SV25Tx and SND1Tx); a toric-extended depth of focus IOL model (Johnson and Johnson Symfony ZXTxxx); and a toric accommodating IOL model (Bausch and Lomb Trulign BL1UT). Patients with more than $0.75 \mathrm{D}$ keratometric astigmatism received an ATIOL combined with a manual limbal relaxing incision (LRI) or an ATIOL with astigmatism (toric) correction depending on either the availability of toric-ATIOLs or recommendation of the supervising surgeon.

All surgeries were performed by third-year residents via phacoemulsification. Primary cases included for this study were defined as cases wherein the resident performed $>75 \%$ of surgical steps during the procedure, including insertion of the ATIOL. The approximate length of ATIOL surgeries varied among the resident surgeons, with most cases requiring 30-40 minutes. Neither intraoperative aberrometry nor femtosecond laser-assisted cataract surgery was performed in any cases as these were not available for resident use at our institution. Residents received an objective assessment (ICO-OSCAR form) after the completion of every ATIOL surgery from the supervising surgeon, as well as subjective comments.

Major outcomes studied were uncorrected distance visual acuity (UDVA), best corrected distance visual acuity (BCDVA), uncorrected intermediate visual acuity (UIVA), uncorrected near visual acuity (UNVA) and postoperative astigmatism. Patients were seen one day, one 
week, one month, and between three to six months (POM3 +) after surgery by both the resident and attending surgeon. Monocular UDVA alone was measured for the 1-day and 1-week visits. UDVA, BCDVA with manifest refraction, binocular UIVA and binocular UNVA were measured at the 1-month and POM3+ visits.

Residents were given an anonymous online questionnaire regarding their experiences with the curriculum, knowledge of ATIOLs, preferences for the studied ATIOL models and current post-residency surgical practice patterns with ATIOLs (Supplemental Material, Exhibit B). Responses to each question were graded using a 5-point Likert scale.

\section{Results}

A total of 12 residents from four residency classes completed the surgical curriculum and performed 122 ATIOL surgeries $(10.17 \pm 6.58)$ during the study period. Figure 1 shows the number of ATIOL surgeries performed by each resident. Table 2 shows the results of an anonymous survey (Supplemental Material, Exhibit B) that asked residents to quantify their level of comfort with aspects of ATIOL surgery as well as post-graduate practice patterns. Notably, all respondents performing cataract surgery ( 8 of 12 residents) after training indicated that their residency experiences helped prepare them for using ATIOLs in their current practice. Figure 2 shows residents' personal preferences regarding ATIOL types.

Due to loss to follow-up after the 1-month postoperative visit (16 eyes) and/or operative complications
(6 eyes), a total of 100 eyes from 72 patients were included in the final analysis of the study. Figure 3 shows the Standard Graphs for Intraocular Lens-Based Refractive Surgery at the POM3+ time point. Table 3 displays the post-operative visual acuity data (UDVA, UIVA and UNVA) for all ATIOL types at the postoperative month 3 or greater (POM3+) timepoint. Postoperative refractive data from astigmatism-correcting ATIOLs were additionally entered into the online doubleangle plot tool to assess the treatment of astigmatism with toric ATIOLs and are shown in Figure $4 .{ }^{9}$

\section{Discussion}

Previous studies have reported favorable visual outcomes of resident-performed cataract surgery with toric IOLs and first-generation ATIOLs by a single manufacturer. ${ }^{10-12}$ During this study, we developed a novel surgical curriculum to teach ophthalmology residents the peri-operative management of all currently available ATIOLs in the United States. The purpose of this study was not to compare the superiority of one ATIOL over another, but rather to demonstrate that resident surgeons can learn to effectively use a diversity of ATIOLs during residency and achieve clinical results that approximate those previously reported for resident-performed cataract surgeries. The encouraging surgical results and novice surgeons' attitudes across four residency classes demonstrate the merits of this curriculum.

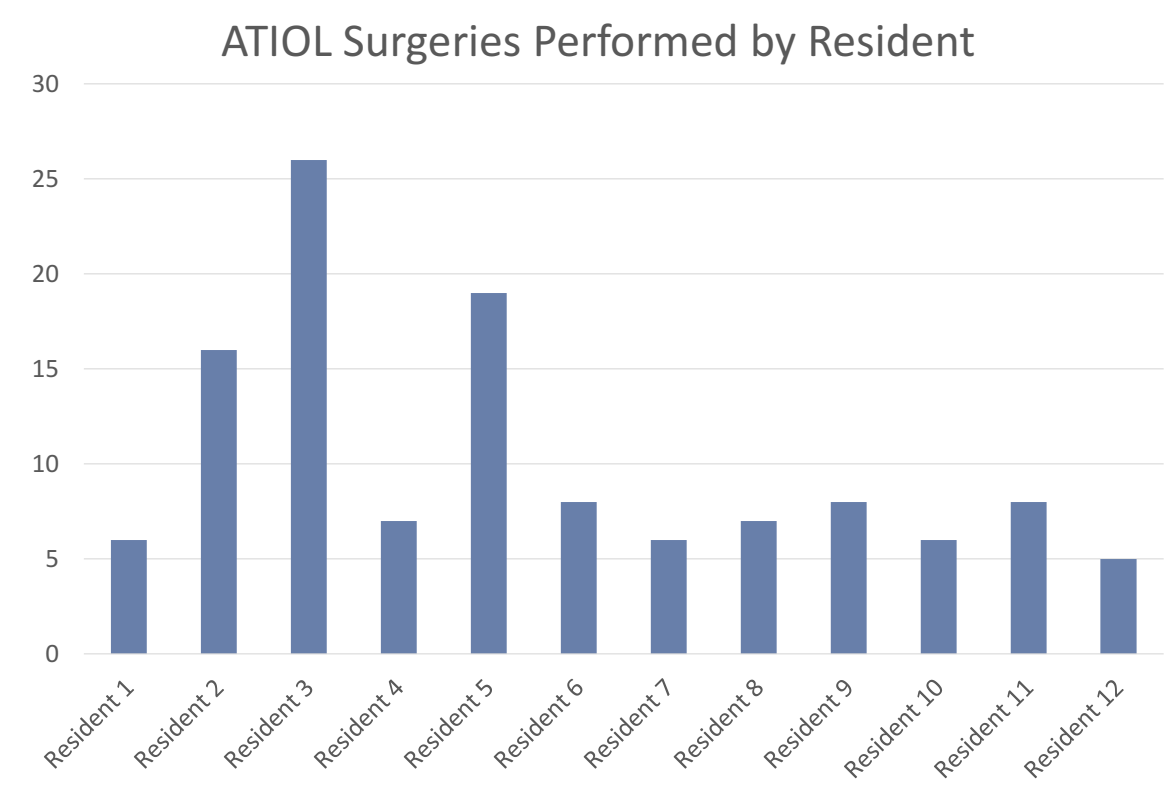

Figure I ATIOL surgeries performed by each resident over four residency classes. 
Table 2 Results of Anonymous Resident Survey After the Completion of the ATIOL Surgical Curriculum*

\begin{tabular}{|c|c|}
\hline Survey Question & $\begin{array}{l}\text { Mean } \\
\text { Score }\end{array}$ \\
\hline $\begin{array}{l}\text { How comfortable (or knowledgeable) do you feel you } \\
\text { are about preoperative knowledge of ATIOLs, } \\
\text { presurgical clinical exam, workup and testing prior to } \\
\text { using ATIOLs }\end{array}$ & $\begin{array}{l}4.50 \pm \\
0.52\end{array}$ \\
\hline $\begin{array}{l}\text { How comfortable (or knowledgeable) do you feel you } \\
\text { are about patient selection for ATIOLs and/or making } \\
\text { recommendations for an ATIOL? }\end{array}$ & $\begin{array}{l}4.08 \pm \\
0.90\end{array}$ \\
\hline $\begin{array}{l}\text { How comfortable (or knowledgeable) do you feel you } \\
\text { are about intraoperative steps that are necessary when } \\
\text { using ATIOLs (eg, marking the patient, inserting the } \\
\text { IOL, aligning the IOL, etc.)? }\end{array}$ & $\begin{array}{l}4.50 \pm \\
0.52\end{array}$ \\
\hline $\begin{array}{l}\text { How comfortable (or knowledgeable) do you feel you } \\
\text { are about postoperative management (including } \\
\text { expectations) of patients who receive ATIOLs? }\end{array}$ & $\begin{array}{l}4.00 \pm \\
0.85\end{array}$ \\
\hline $\begin{array}{l}\text { To what degree do you think that currently available } \\
\text { ATIOLs will provide spectacle independence for all } \\
\text { three zones of vision (distance, intermediate and near) } \\
\text { for patients? }\end{array}$ & $\begin{array}{l}3.58 \pm \\
1.00\end{array}$ \\
\hline $\begin{array}{l}\text { Do you feel that your residency experiences helped to } \\
\text { better prepare you for using ATIOLs in your future or } \\
\text { current practice? }\end{array}$ & $\begin{array}{l}4.63 \pm \\
0.48\end{array}$ \\
\hline $\begin{array}{l}\text { To what degree do you think you will use ATIOLs (or } \\
\text { are currently using ATIOLs) in your surgical practice } \\
\text { after residency? }\end{array}$ & $\begin{array}{l}4.38 \pm \\
0.48\end{array}$ \\
\hline
\end{tabular}

Notes: Residents were asked to rank from I ("not at all”) to 5 ("a great deal”) how comfortable (or knowledgeable) do you feel with each step of ATIOL surgery?

*Four respondents indicated that they are practicing surgical retina and do not/will not perform cataract surgery after residency.

Residents felt the curriculum increased their knowledge and comfort with ATIOL surgery. All (8/8) postgraduate surgeons practicing cataract surgery affirmed that their residency experiences helped prepare them for using ATIOLs in their current practice environments. Residents had slightly less enthusiastic attitudes about the actual effectiveness of ATIOLs. Interestingly, residents had varying attitudes in regards to their preference for a given ATIOL; in general, for both non-toric and toric ATIOLs, residents most preferred using EDOF IOLs and least preferred AIOLs. The relatively recent introduction of this "new" ATIOL (August 2016) to market during the study period may partially explain this enthusiasm.

Our results show that residents can achieve excellent visual outcomes after ATIOL surgery similar to those

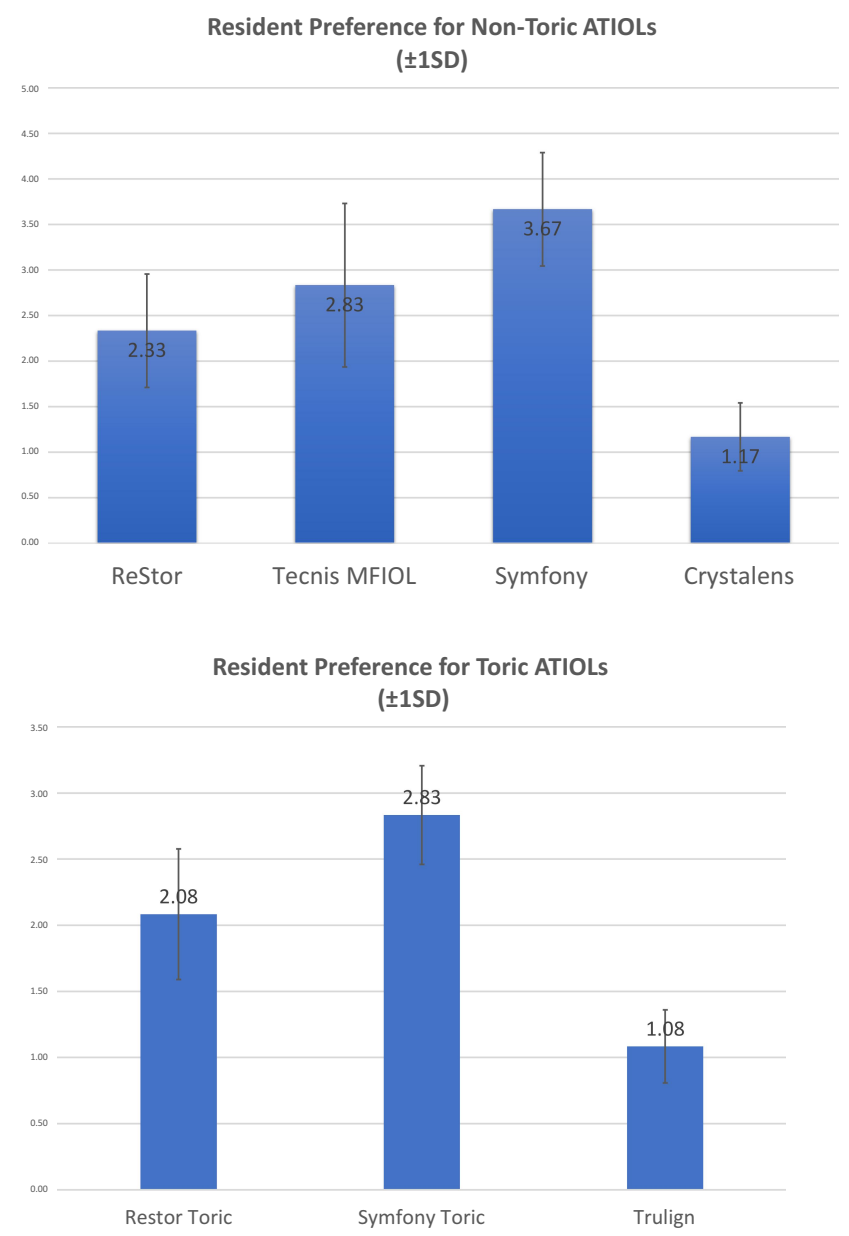

Figure 2 Resident preferences for ATIOLs implanted during the study. Panel (A) shows preferences for non-toric ATIOLs (scale I-4; 4 most preferred) and Panel (B) shows preferences for toric ATIOLs (scale I-3; 3 most preferred).

reported by experienced surgeons. ${ }^{13-15}$ The majority of patients achieved good UDVA, UIVA and UNVA (88\%, $93 \%$, and $71 \%$, respectively) at the POM3 + timepoint. Our UDVA results with ATIOLs are comparable to the UDVA results of resident-performed standard cataract surgery reported in several studies. ${ }^{6-8}$ Among the studied ATIOLs, AIOLs had good UIVA but did not perform as well for UDVA and UNVA at POM3+, which is similar to experienced surgeons' results in the literature. ${ }^{15}$ This may also explain residents' lower preferences for this model. In both the wet-lab and operating room, we observed that AIOLs require additional surgical dexterity compared to the other ATIOL models, especially with the insertion maneuver. Due to this learning curve, it is possible that with more experience with AIOLs, novice surgeon results may improve over time. Finally, the excellent results for toric ATIOLs to reduce astigmatism in our study are especially promising. 
A

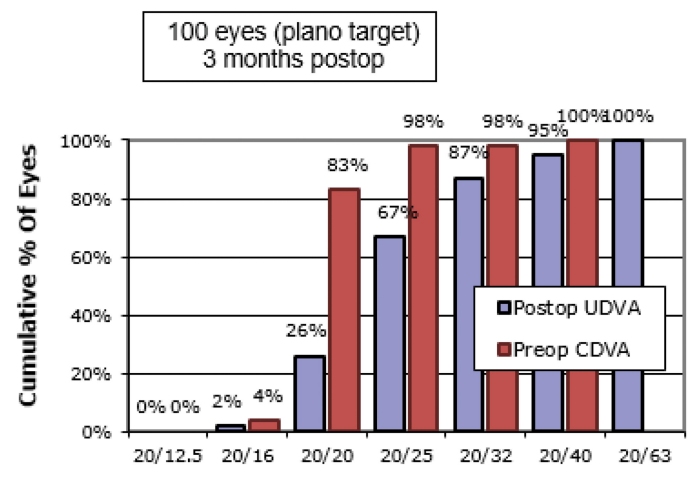

Cumulative Snellen Visual Acuity (20/x or better)
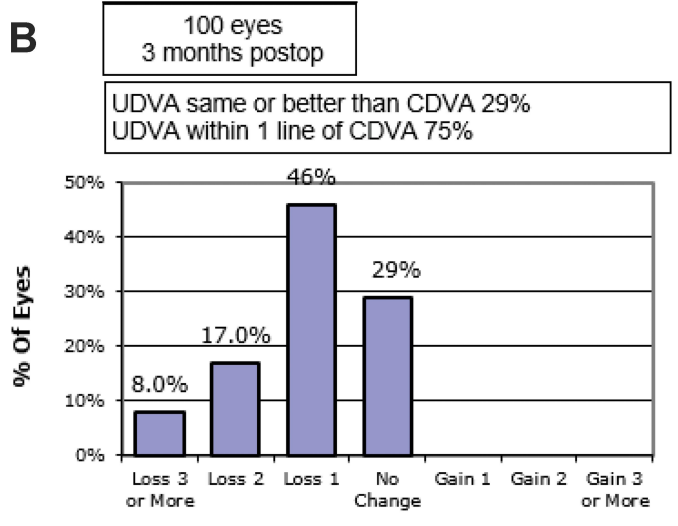

Difference between UDVA and CDVA (Snellen Lines) at 3 months postop

\section{Uncorrected Distance Visual Acuity}

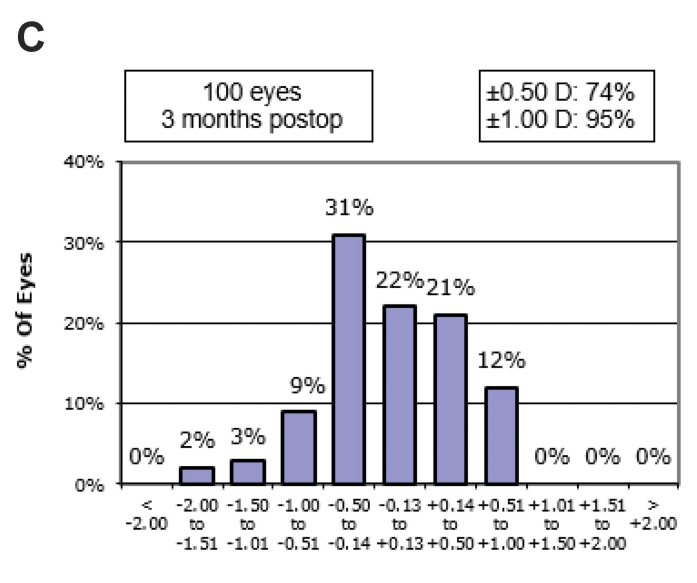

Postoperative Spherical Equivalent Refraction (D)

\section{Uncorrected Distance Visual Acuity vs Corrected Distance Visual Acuity}
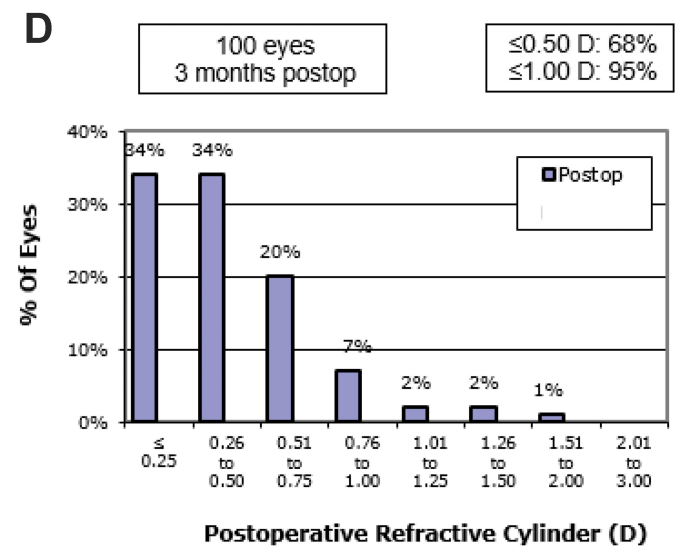

Refractive Cylinder

Spherical Equivalent Refractive Accuracy

Figure 3 Four Standard Graphs for Intraocular Lens-Based Refractive Surgery at POM3+. Panel (A) displays a comparison of preoperative corrected distance visual acuity with postoperative uncorrected distance visual acuity. Panel (B) shows a comparison of postoperative uncorrected distance visual acuity with corrected distance visual acuity. Panel (C) displays spherical equivalent (SE) refractive accuracy of target SE compared with actual SE. Panel (D) displays the postoperative refractive cylinder values.

The intra-operative complication rate of residentperformed ATIOL surgeries, including posterior capsule rupture $(6.7 \%)$, is comparable to previously reported resident cataract surgery complication rates. ${ }^{16-19}$ Reviewing these results, we observed the inclusion of ATIOL surgery to our curriculum did not lead to increased or unacceptable complication rates when compared to standard cataract surgery alone. Out of 122 surgeries performed for this study, there were six patients $(4.9 \%)$ that were excluded due to various intraoperative complications, which is within the expected range of surgeons in training. These patients were successfully managed by the attending surgeon completing the surgery as the primary surgeon; none of these six patients required additional surgical procedures or experienced vision loss postoperatively. An additional 15 eyes were excluded due to lack of follow-up at the POM3+ visit. One patient with a toric ATIOL (included in final analysis) required a return to the operating room due to postoperative rotation of the ATIOL; in this case, the ATIOL was rotated successfully without any further complications. Finally, one patient reported intractable glare and haloes persisting six months after surgery requiring removal of the ATIOL and placement of a monofocal IOL (not included in final analysis); this patient experienced no further complications.

Resident-performed cataract surgery already includes additional costs in the form of increased operating room time and faculty involvement. ${ }^{20,21}$ Introducing a supplemental 
Table 3 Visual Acuity Results at POM3+ for All ATIOLs Used in This Study

\begin{tabular}{|l|l|l|l|l|l|}
\hline & ATIOL Model & $\begin{array}{l}\text { Number of } \\
\text { ATIOLs }\end{array}$ & $\begin{array}{l}\text { N (\%) UDVA of } \\
\mathbf{2 0 / 3 0}\end{array}$ & $\begin{array}{l}\text { N (\%) UIVA of } \\
\mathbf{2 0 / 3 0}\end{array}$ & $\begin{array}{l}\text { N (\%) UNVA of } \\
\mathbf{2 0 / 3 0}\end{array}$ \\
\hline Diffractive MFIOLs & $\begin{array}{l}\text { ZKBOO, ZLBOO, } \\
\text { ZMBOO } \\
\text { SN6ADI, SV25TO }\end{array}$ & 38 & $37(97.4)$ & $37(97.4)$ & $34(89.5)$ \\
\hline EDOF-IOLs & ZXROO & 19 & $6(100)$ & $6(100)$ & $5(83)$ \\
\hline Accommodating IOLs & AOIUV & 14 & $18(94.7)$ & $17(89.5)$ & $10(52.6)$ \\
\hline $\begin{array}{l}\text { Astigmatism-Correcting } \\
\text { IOLs }\end{array}$ & SNDITx, SV25Tx & 7 & $6(85.7)$ & $13(92.9)$ & $11(78.6)$ \\
\hline & ZXTxxx & 7 & 9 & $5(71.4)$ & $3(42.9)$ \\
\hline & BLIUT & 100 & $88(88)$ & $8(100)$ & $4(57.1)$ \\
\hline Totals & & $98.4)$ & $93(93)$ & $4(44.4)$ \\
\hline
\end{tabular}

Notes: Uncorrected distance visual acuity (UDVA), uncorrected intermediate visual acuity (UIVA), and uncorrected near visual acuity (UIVA) were measured. UDVA was measured monocularly and UIVA and UNVA were measured binocularly.

curriculum places additional resource demands on a training program and must be deliberately integrated within other existing surgical curricula and training requirements for residents. For the ATIOL curriculum, additional faculty time was required for the conception and implementation of the educational program. For example, Phase 1 required approximately 4-8 hours for lectures and wet-lab practice. Materials required for the wet-lab were acquired gratis from the educational training instruments and models provided to residents by the ATIOL manufacturers; no additional costs were incurred by the residency program. The other two phases did not significantly add additional time or resources as these were incorporated into the routine clinical care of patients. The addition of an ATIOL curriculum did not adversely affect primary surgical education objectives; all of the residents involved in the study exceeded the required ACGME criteria for cataract surgeries (average 187.17 \pm 47.58 ). As described above, we were able to successfully implement this curriculum across four residency classes. In this case, having the same teaching surgeon allowed for consistency in education and surgical supervision to all residents in the study, although other programs could choose to expand the number of faculty to distribute the teaching responsibilities.

A strength of our curriculum lies in a stepwise, progression-of-phases model with objective and subjective metrics that successfully incorporates the use of these ATIOLs. We were especially motivated to develop a curriculum that included the full spectrum of available ATIOLs in order to not only educate trainees, but also to minimize bias or preference for a given ATIOL from the surgical educator. We approached all three ATIOL manufacturers with our request for practice instruments and models equally. However, all educational materials (didactic lectures, tests, etc.) were developed internally by the surgical educator without manufacturer influence. Residents also had opportunities to practice in the wet lab with each ATIOL during Phase 1. Therefore, we believe it is both possible and ideal for this curriculum to exist without undue industry involvement or bias.

This study has several limitations. First, only 3 months of follow-up was required to be included in the study. Although many of the patients had 1-year follow-up data that were used when available, a significant number of patients lacked refractive data after the POM3+ visit, and therefore we are unable to report the long-term refractive results of our study population. Second, though there was discussion among the patient, attending surgeon and resident surgeon regarding ATIOL options, the final decision for ATIOL model was, of course, left to the patient. As a result, we observed a discrepancy among the number of ATIOLs across the various models in this study. We also observed that several resident surgeons performed more ATIOL surgeries than others (Table 2). This is expected in a resident surgery population and may be explained by a variety of reasons, including but not limited to: availability of suitable patients for ATIOL surgery and time of the academic year when the resident surgeon was on the attending surgeon's rotation; resident surgeon skill level; and variable motivation levels of residents to perform ATIOL surgery. Moreover, due to patient preferences, the 


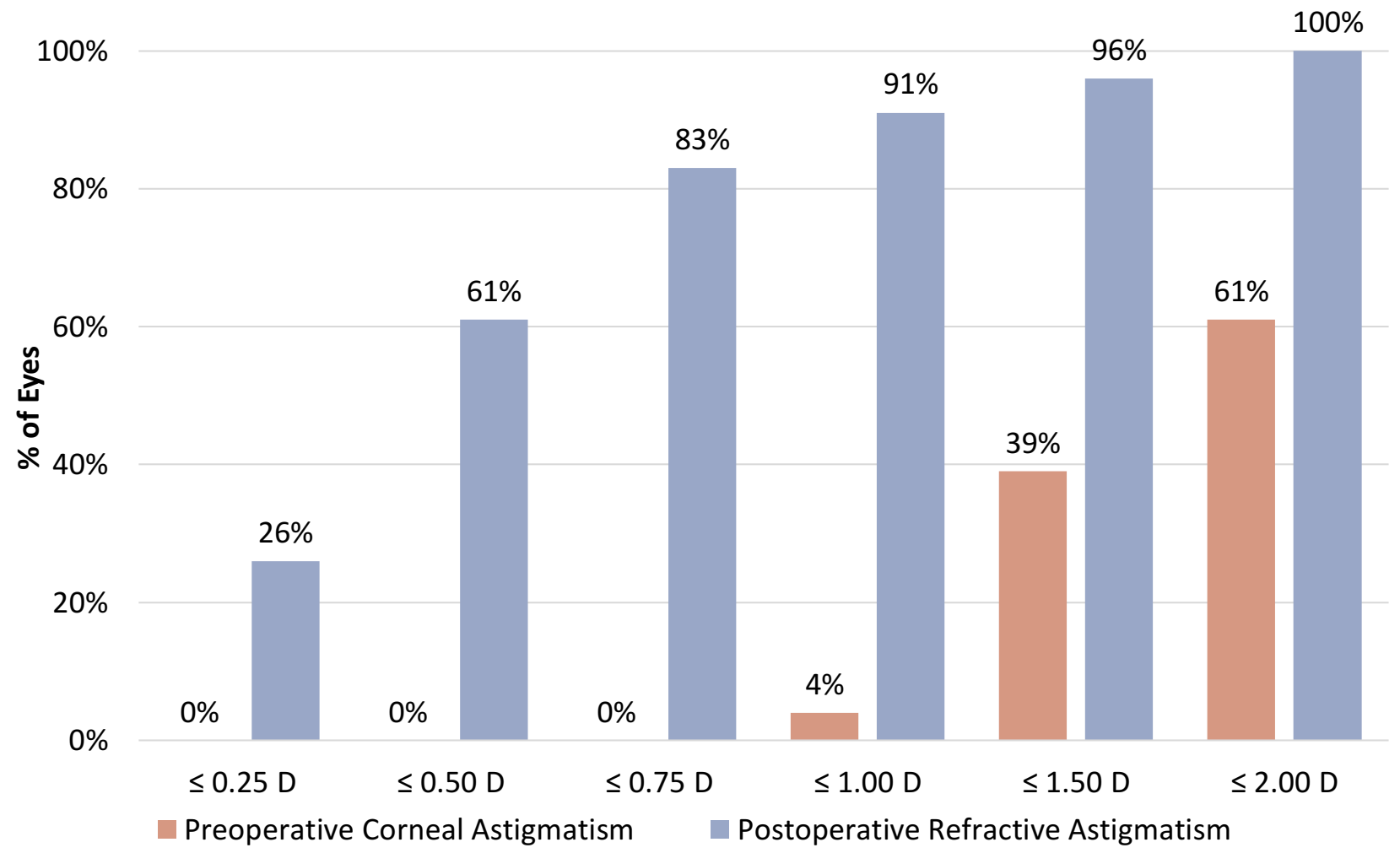

\begin{tabular}{l|c|c|c|c|}
\multicolumn{4}{c}{ Preoperative Corneal Astigmatism } & \multicolumn{2}{c|}{ Postoperative Refractive Astigmatism } \\
\cline { 2 - 5 }$\leq 0.25 \mathrm{D}$ & 0 & $0 \%$ & 6 & $26 \%$ \\
\hline$\leq 0.50 \mathrm{D}$ & 0 & $0 \%$ & 14 & $61 \%$ \\
\hline$\leq 0.75 \mathrm{D}$ & 0 & $0 \%$ & 19 & $83 \%$ \\
\hline$\leq 1.00 \mathrm{D}$ & 1 & $4 \%$ & 21 & $91 \%$ \\
\hline$\leq 1.50 \mathrm{D}$ & 9 & $39 \%$ & 22 & $96 \%$ \\
\hline$\leq 2.00 \mathrm{D}$ & 14 & $61 \%$ & 23 & $100 \%$ \\
\hline
\end{tabular}

Figure 4 Preoperative corneal astigmatism and postoperative refractive astigmatism graph and double-angle astigmatism plots for toric ATIOLs at POM3+.

final distribution of chosen ATIOLs significantly favored diffractive MFIOLs followed by EDOF IOLs. However, we believe this discrepancy furthers our assertion that we did not perform this study to assess or compare the superiority of a particular ATIOL as our study was not sufficiently powered to ensure equality among studied ATIOL models. Third, patient satisfaction surveys were not administered to assess the patients' subjective experience with ATIOLs after surgery, especially with long-term satisfaction or level of spectacle independence after three months. Fourth, while all patients were pseudophakic at the time of POM3 + binocular UIVA and UNVA testing, some patients had ATIOLs in both eyes and others only had an ATIOL in one eye (with a monofocal IOL in the fellow eye). These fellow eyes, though used for binocular UIVA and UNVA for the included eyes, did not meet the follow-up criteria and thus were not included in the final analysis. This high rate of loss to follow-up is not unsurprising for a resident surgical population. Nevertheless, our refractive results can at best be used to demonstrate non-inferiority of resident-performed ATIOL surgeries rather than be used as a comparative benchmark among ATIOL surgery studies comparing visual outcomes with more rigorous study designs.

In addition, this study took place at one academic institution with one teaching attending (KMR) involved at both the curriculum and surgical supervision levels. An ideal next step would be to expand this curriculum to multiple academic centers and perform a prospective study with this surgical curriculum (including any 
necessary modifications). Other steps would include the involvement of multiple experienced surgical educators to further refine the didactic lectures and assessment test(s) (Phase 1); the description of specific wet-lab objectives and proficiency assessments (Phase 1); and the development of objective assessment tools of ATIOL surgery (similar to the ICO-OSCAR form used for standard cataract surgery) (Phase 3). Additionally, we did not perform pre-curriculum surveys to assess our residents' knowledge of ATIOL surgery; thus, quantitative assessment of beforeand after-effects of the ATIOL curriculum was not available. Finally, a more standardized approach to ensure an equal number of ATIOL models, though challenging to implement, may also provide useful information for better comparison among ATIOL models in future studies.

\section{Conclusion}

Our results show that a stepwise curriculum can be safely, efficiently, and effectively implemented to teach resident surgeons regarding the full spectrum of available ATIOLs, especially when preoperative, intraoperative, and postoperative care is supervised appropriately. Residents' experiences with ATIOLs serve to enhance their residency training and may better prepare them for a post-residency surgical practice that requires an ability to manage ATIOLs that is not currently an educational requirement in ophthalmology. Educators may be encouraged by our prototype ATIOL curriculum and surgical results to implement and further expand the use of available ATIOLs into their own respective surgical educational programs.

\section{Disclosure}

Meeting Presentations: Free paper session at American Society of Cataract and Refractive Surgery 2019 Annual Symposium and Congress, Washington, DC, USA; April 2019. None of the authors have financial disclosures in regards to the conception, data, studied devices and results of this manuscript. Dr Williams and Dr Kloek additionally have no unrelated financial disclosures outside of this work. Dr Riaz has unrelated financial disclosures outside of this work: speaker for Bausch and Lomb and as a speaker and consultant for Beaver-Visitec. Dr Farooq has unrelated financial disclosures outside of this work: consultant for GlaxoSmithKline and reports personal fees from GlaxoSmithKline and Akorn, outside the submitted work. This research did not receive any specific grant from funding agencies in the public, commercial, or not-for-profit sectors. The authors report no other potential conflicts of interest in this work.

\section{References}

1. American Society of Cataract and Refractive Surgery. ASCRS clinical survey; 2018. Available from: http://supplements.eyeworld.org/ eyeworld-supplements/december-2018-clinical-survey. Accessed January 10, 2020.

2. Yen AJ, Ramanathan S. Advanced cataract learning experience in United States ophthalmology residency programs. J Cataract Refract Surg. 2017;43:1350-1355. doi:10.1016/j.jcrs.2017.10.014

3. Yeu E, Reeves SW, Wang L, Randleman JB. Resident surgical experience with lens and corneal refractive surgery: a survey of the ASCRS young physicians and residents membership. $J$ Cataract Refract Surg. 2013;39:279-284. doi:10.1016/j.jcrs.2012.09.029

4. Schallhorn JM, Ciralsky JB, Yeu E. Resident and young physician experience with complex cataract surgery and new cataract and refractive technology: results of the ASCRS 2016 young eye surgeons survey. $J$ Cataract Refract Surg. 2017;43:687-694. doi:10.1016/j.jcrs.2017.04.022

5. Randleman JB, Wolfe JD, Woodward M. The resident surgeon phacoemulsification learning curve. Arch Ophthalmol. 2007;125:1215-1219. doi:10.1001/archopht.125.9.1215

6. Payal AR, Gonzalez-Gonzalez LA, Chen X, et al. Outcomes of cataract surgery with residents as primary surgeons in the veterans affairs healthcare system. $J$ Cataract Refract Surg. 2016;42:370-384. doi:10.1016/j.jcrs.2015.11.041

7. Finn AP, Borboli-Gerogiannis S, Brauner S, et al. Assessing resident cataract surgery outcomes using medicare physician quality reporting system measures. J Surg Educ. 2016;73:774-779. doi:10.1016/j. jsurg.2016.04.007

8. Kaplowitz K, Yazdanie M, Abazari A. A review of teaching methods and outcomes of resident phacoemulsification. Surv of Ophthalmol. 2018;63:257-267. doi:10.1016/j.survophthal.2017.09.006

9. American Society of Cataract and Refractive Surgery. ASCRS double angle plot tool; 2019. Available from: $<$ http://ascrs.org/astigmatismdouble-angle-plot-tool" $>$ " $><$ http://ascrs.org/astigmatism-doubleangle-plot-tool>. Accessed January 10, 2020.

10. Sundy M, McKnight D, Eck C, Rieger F. Visual acuity outcomes of toric lens implantation in patients undergoing cataract surgery at a residency training program. Mo Med. 2016;113:40-43.

11. Pouyeh B, Galor A, Junk AK, et al. Surgical and refractive outcomes of cataract surgery with toric intraocular lens implantation at a resident-teaching institution. $J$ Cataract Refract Surg. 2011;37:1623-1628. doi:10.1016/j.jcrs.2011.03.050

12. Roensch MA, Charton JW, Blomquist PH, Aggarwal NK, McCulley JP. Resident experience with toric and multifocal intraocular lenses in a public county hospital system. $J$ Cataract Refract Surg. 2012;38:793-798. doi:10.1016/j.jcrs.2011.11.043

13. Cochener B, Lafuma A, Khoshnood B, Courouve L, Berdeaux G. Comparison of outcomes with multifocal intraocular lenses: a meta-analysis. Clin Ophthalmol. 2011;5:45-56. doi:10.2147/OPTH. S14325

14. Torun Acar B, Duman E, Simsek S. Clinical outcomes of a new diffractive trifocal intraocular lens with Enhanced Depth of Focus (EDOF). BMC Ophthalmol. 2016;16:208. doi:10.1186/s12886-016-0389-8

15. Zvornicanin J, Zvornicanin E. Premium intraocular lenses: the past, present and future. J Curr Ophthalmol. 2018;30:287-296. doi:10.1016/j.joco.2018.04.003

16. Briszi A, Prahs P, Hillenkamp J, Helbig H, Herrmann W. Complication rate and risk factors for intraoperative complications in resident-performed phacoemulsification surgery. Graefe's Arch Clin Exp Ophthalmol. 2012;250:1315-1320. doi:10.1007/s00417012-2003-y

17. Rutar T, Porco TC, Naseri A. Risk factors for intraoperative complications in resident-performed phacoemulsification surgery. Ophthalmology. 2009;116:431-436. doi:10.1016/j.ophtha.2008. 10.028 
18. Woodfield AS, Gower EW, Cassard SD, Ramanthan S. Intraoperative phacoemulsification complication rates of second- and third-year ophthalmology residents: a 5-year comparison. Ophthalmology. 2011;118:954-958. doi:10.1016/j.ophtha.2010.08.047

19. Bhagat N, Nissirios $N$, Potdevin L, et al. Complications in resident-performed phacoemulsification cataract surgery at New Jersey Medical School. Br J Ophthalmol. 2007;91:1315-1317. doi:10.1136/bjo.2006.111971
20. Taravella MJ, Davidson R, Erlanger M, Guiton G, Gregory D. Time and cost of teaching cataract surgery. J Cataract Refract Surg. 2014;40:212-216. doi:10.1016/j.jcrs.2013.07.045

21. Hosler MR, Scott IU, Kunselman AR, Wolford KR, Oltra EZ, Murray WB. Impact of resident participation in cataract surgery on operative time and cost. Ophthalmology. 2012;119:95-98. doi:10.1016/j.ophtha.2011.06.026

\section{Publish your work in this journal}

Clinical Ophthalmology is an international, peer-reviewed journal covering all subspecialties within ophthalmology. Key topics include: Optometry; Visual science; Pharmacology and drug therapy in eye diseases; Basic Sciences; Primary and Secondary eye care; Patient Safety and Quality of Care Improvements. This journal is indexed on PubMed

Submit your manuscript here: https://www.dovepress.com/clinical-ophthalmology-journal
Central and CAS, and is the official journal of The Society of Clinical Ophthalmology (SCO). The manuscript management system is completely online and includes a very quick and fair peer-review system, which is all easy to use. Visit http://www.dovepress.com/ testimonials.php to read real quotes from published authors. 